\title{
Description of the immature stages of the weevil Anthonomus vis Clark (Coleoptera, Curculionidae), inquiline into the gall of Leandra aurea (Melastomataceae)
}

\author{
Daniela de Cassia Bená ${ }^{1,2} \&$ Sergio Antonio Vanin ${ }^{1}$
}

\begin{abstract}
'Departamento de Zoologia, Instituto de Biociências, Universidade de São Paulo, Rua do Matão, Travessa 14, 101, 05508-900 São Paulo-SP, Brazil. savanin@ib.usp.br

${ }^{2}$ Museu de Zoologia, Universidade de São Paulo, Av. Nazaré 481, 04263-000 São Paulo-SP, Brazil. danicoleoptera@gmail.com.
\end{abstract}

\begin{abstract}
Description of the immature stages of the weevil Anthonomus vis Clark (Coleoptera, Curculionidae), inquiline into the gall of Leandra aurea (Melastomataceae). The third instar larva and the pupa of Anthonomus vis Clark, 1992 are described and illustrated, based upon specimens collected in the Serra de São José, Tiradentes, in Minas Gerais, southeastern Brazil. The species was previously known from the type series collected in the states of Amapá and Pará. Comparisons with the larva and pupa of $A$. grandis Boheman, 1843 and A. monostigma Champion, 1903 are included. The larvae of $A$. vis live as inquilines in the galls induced by a species of momphid moths (Lepidoptera, Momphidae) in the stems of Leandra aurea (Cham.) Cogn. (Melastomataceae).
\end{abstract}

KEYWORDS. Anthonomini; bionomy; Curculioninae; Insecta; Neotropical.

Anthonomus Germar has a very wide distribution, occurring in the following regions: Holarctic, Neotropical, Afrotropical (Guinea), and Oriental (China, Taiwan, Java, Borneo) (Alonso-Zarazaga \& Lyal 1999). In the Americas, 290 species are recorded, 72 of which are in South America and 19 in Brazil (O’Brien \& Wibmer 1982; Wibmer \& O'Brien 1986), but many species have since been described following the publication of these two checklists. According to Clark (2013), who described 246 new species of Anthonomus from 1985 to 2010, this includes about 500 worldwide species, of which 400 are distributed in the neotropics.

Bionomical knowledge about the genus was restricted to a few species with economic importance, such as the cotton boll weevil, A. grandis Boheman, 1843 (Burke 1976), but has increased in recent years, especially due to the potential use of Anthonomus weevils as biological control agents for invasive plants of South American origin (Chacón-Madrigal et al. 2012).

When A. vis Clark, 1992 was described, nothing was known about plant associations or other biological data (Clark 1992). Subsequently, Maia \& Fernandes (2004) and Maia \& Oliveira (2004) reported immatures of this species living as inquilines in galls induced by a momphid moth (Lepidoptera, Momphidae) in Leandra aurea (Cham.) Cogn. (Melastomataceae). The weevil species was identified on that occasion (Maia \& Fernandes 2004) as Anthonomus sp. nov. by the second author (SAV). As the knowledge on immatures of Anthonomus is very scarce, herein we provide a description of the larva and the pupa of $A$. vis.

\section{MATERIAL AND METHODS}

The studied material was collected by Dr. Valéria Cid Maia, during her research studies on inquilines and inducers of galls, conducted in the Serra de São José, an area of rupestrian fields enclosed by "cerrado" vegetation (savanna), in municipality of Tiradentes, Minas Gerais, southeastern Brazil (Maia \& Fernandes 2004). The species was identified using Clark's (1992) key, through the examination of the male genitalia, and comparison with the holotype and paratypes deposited at the Museu de Zoologia, Universidade de São Paulo (MZSP). Immatures and adults are deposited at the entomological collection of the MZSP.

Last instar larvae were dissected in water, under a Wild M5A stereomicroscope. Temporary slides were prepared using $100 \%$ glycerin medium. Drawings were done with the aid of a camera lucida adapted to the stereomicroscope or a Leitz Microscope SM-Lux. The final line drawings were done with ink and drafting paper. All images went through digital processing (Adobe Photoshop CS3). Measurements were made with an eyepiece micrometric scale in the stereomicroscope; values are given in millimeters. The terminology and abbreviations used in the larval and pupal descriptions follow May (1994). Photographs of the adult weevils (Figs. 1,2 ) were taken with a stereomicroscope Leica M125 with a coupled magnifier in a DV camera mounted on a Leica DFC.

\section{RESULTS}

\section{Anthonomus vis Clark, 1992}

(Figs. 3-27)

Description of mature larva (third instar) (Figs. 3-24). Length: $3 \mathrm{~mm}$; prothorax width: $1.4 \mathrm{~mm}$; head capsule width: $1.7 \mathrm{~mm}$; body sub-cylindrical, strongly curved dorsoventrally, thoracic segments 2 and 3 sub-equal, segment 1 narrower than 2 and 3, last four abdominal segments strongly convergent posteriad (Fig. 3). Head capsule light yellow to 

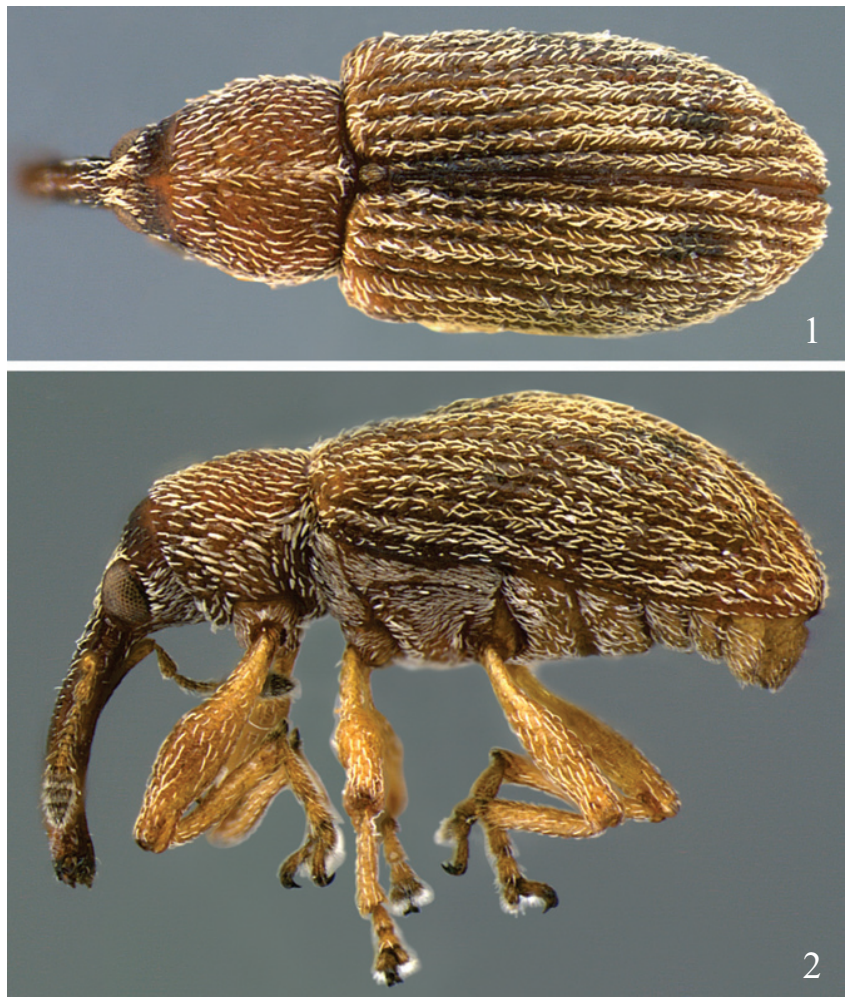

Figs. 1-2. Anthonomus vis. 1, adult, dorsal view; 2, adult, lateral view.

yellowish-brown, mandibles darker; prothorax and abdomen creamy white, pronotal shields light yellow to yellowishbrown; body setae short and fine.

Head (Figs. 4, 5). Hypognathous, sclerotized, free, head capsule slightly wider than long, sides rounded. Epicranial suture distinct, approximately 0.55 times as long as head capsule. Frontal suture distinct, complete, weakly sinuate, Vshaped. Median endocarina present, about 0.26 times as long as head capsule. One stemma present on each side. Antennae exposed (Figs. 6, 7), one-segmented, conical, accessory appendage elongate, about three times as long as basal width, and with five minute processes, three longer and two very short. Head capsule (Fig. 4) with four pairs of short posterior epicranial setae (pes1-pes4), aligned vertically; four pairs of dorsal epicranial setae (des 1-des 4$)$, des 4 the longest; five pairs of frontal setae $\left(f_{s} 1-f_{s} 5\right), f_{s} 2$ inserted close to frontal suture, and $f_{S} 5$ the longest, tip surpassing clypeo-labral suture; two pairs of lateral epicranial setae (les1, les2), subequal in length; two pairs of ventral epicranial setae (ves), ves 2 slightly longer than ves1. Epistomal and frontoclypeal sutures slightly arcuate. Clypeus (Figs. 4-6) transverse, lateral margins rounded, anterior margin sinuate, with three pairs of very small clypeal setae (cls1-cls3). Labrum (Fig. 6) transverse, anterior margin emarginated, with three pairs of labral setae (lrms1-lrms3), lrms3 slightly longer than lrms 1 and lrms2. Epipharynx (Fig. 6) trapezoidal, rounded anteriorly, with a transverse row of four anteromedian setae ( $a m s)$, three pairs of anterolateral setae (als1-als3) on each side, two pairs of median setae (mes); subparallel labral rods (lr) elongated, diverging anteriorly; four epipharyngeal sensory pores arranged in two clusters. Maxillae (Figs. 9, 10) with one short seta on basal third and one longer seta near anterior margin on dorsal side and with three setae on ventral side; mala rounded, with six marginal dorsal spatulate setae more or less aligned along outer margin (Fig. 9) and three smaller ventral setae; palpifer membranous; maxillary palpus twosegmented, proximal palpomere larger than distal one, with one seta and three sensilla on ventral side; distal palpomere with one sensillum on ventral side. Labium (Fig. 10): labial palpi two-segmented, basal palpomere transverse, distal palpomere longer than wide, each palpomere with three ventral sensilla; prementum with three pairs of setae, posterior pair longest; premental sclerite with latero-posterior margin strongly reduced; submentum with three pairs of setae, posterior pair longest; ligula without sensilla. Mandibles symmetrical (Figs 11,12), stout, apically bidentate, dorsally with two setae $(m d s)$ and one minute sensillum on dorsum.

Thorax (Figs. 16, 19, 22). Pro-, meso- and metathorax transverse, each one narrower than abdomen. Prothorax with 11 pronotal setae (prns 1-prns 11) on each side: prns 1-prns4 near anterior margin, prns 5 very small and short, prn6 longest, prn7prns11 aligned near posterior margin; pedal area with three pedal setae (pdas1-pdas3); ventropleural lobe with two setae (vpls1-vpls2); mediosternal fold with two mediosternal setae (msts1-msts2). Meso- and metathorax: prodorsum of mesoand metathorax with one pair of prodorsal setae (prs), postdorsum of meso- and metathorax with five dorsolateral setae ( $d l s 1-d l s 5)$; spiracular area of meso- and metathorax with three spiracular setae (ss 1-ss3), ss 2 much smaller than $s s 1$ and $s s 3$; dorsopleural lobe of meso- and metathorax with one dorsopleural lobe seta $(d p l s)$; ventropleural lobe of meso- and metathorax with one ventropleural seta $(v p l s)$; mediosternal lobe with one seta (msts). Prothoracic spiracle (Fig. 13) annular, biforous, air tubes with five annuli directed upwards, peritreme irregularly oval.

Abdomen (Figs. 17, 18, 20, 21, 23, 24) with 8 pairs of lateral spiracles (Figs. 14, 15), bicameral, peritreme circular, air tubes with five annuli; spiracles of abdominal segments I-VII similar, obliquely caudad, spiracles of segment VIII smaller, with air tubes directed ventrad; segments I-VII each one with three folds; segment VIII with two folds; segment IX with one fold; segment $\mathrm{X}$ reduced, circular and ventral, anus subterminal, opening in middle of four prominent lobes; segments I-VII with similar chaetotaxy (Figs. 17, 20, 23): prodorsum with a pair of prodorsal setae (prs); spiracular area with two minute setae (ss1-ss2); postdorsum with tranverse row of five pairs of laterodorsal setae (lds l-lds5); ventropleural lobe and laterosternal lobe with one seta ( $v p l s$, $l s t s$ ); mediosternal fold with two very long setae ( $m s t s 1$ msts 2); chaetotaxy of segment VIII (Figs. 18, 21, 24) similar to segments I-VII, but pro-dorsal setae (prs) absent; segment $\mathrm{X}$ rounded, reduced, surrounded by four fleshy lobes.

Description of female pupa (Figs. 25, 27). Length: 3.2 $\mathrm{mm}$. Adecticous and exarate. Coloration whitish-cream, with long, stiff setae on pronotum, smaller setae on rostrum and 

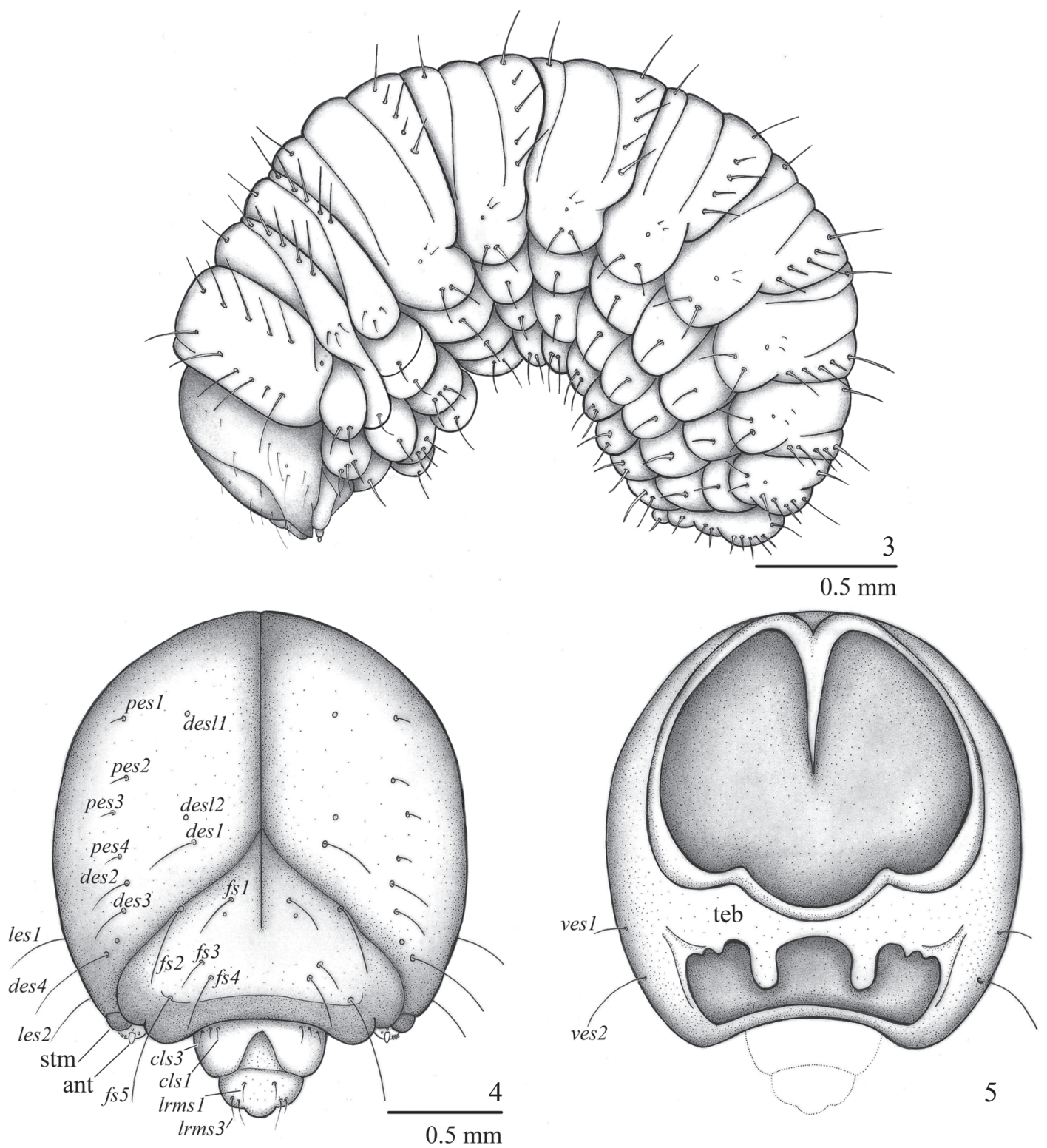

Figs. 3-5. Anthonomus vis, third instar larva. 3, habitus of larva (lateral view); 4, head capsule (frontal view); 5, head capsule (posterior view). Legends [seta(ae), s.]: ams, anteromedian s.; als, anterolateral s.; ant, antenna; cls, clypeal s.; esm, epistoma; des, dorsal epicranial s.; fs, frontal s.; teb, tentorial bracon; les, lateral epicranial s.; lrms, labral s.

very small setae placed on spiniform processes on dorsal side of abdomen. Head almost completely covered by pronotum in dorsal view; each side with one vertical seta $(v s)$, one pair of minute supraorbital setae (sos) and two pairs of orbital setae (os 1-os2) located near eye margin; rostrum short, apex just surpassing anterior coxae; rostrum with one pair of short post-antennal setae (pas) and two pairs of rostral setae (rs 1$r s 2)$. Prothorax transverse, conical; one pair of suprapical setae (sas) and one pair of discal setae $(d s)$ located on prominent spiniform processes, and with three lateral setae (ls 1 $\left.l_{s} 3\right)$ and four posterolateral setae $(p l s 1-p l s 4)$ on each side. Mesothorax (ThII) with three erect, fine tergal setae on each side, located at sides of rounded scutellum. Metathorax sulcate at middle, with three pairs of posterior tergal setae on each side. Abdomen: segments I-VIII with four pairs of tergal setae located on small spiniform processes, forming one transverse row close to posterior margin; III and IV slightly wider than others; VIII transverse with anterior margin rounded; IX with pseudocerci $(p c)$ transverse, not pedunculate, minutely setose at apex. Seven annular spiracles placed at lateral sides of segments I to VII, clearly visible only in lateral view.

Material examined. BRAZIL. Minas Gerais: Tiradentes, Serra de São José, 21 ${ }^{\circ} 03-07^{\prime} \mathrm{S}$ and $44^{\circ} 06-13^{\prime} \mathrm{W}$; 2 larvae (1 dissected), 1 pupa, 8 adults (1 male and 1 female dissected) (MZSP).

Host plant. Leandra aurea (Melastomataceae). Scrub-like, 2-3 $\mathrm{m}$ in height, densely pubescent. The species is endemic 


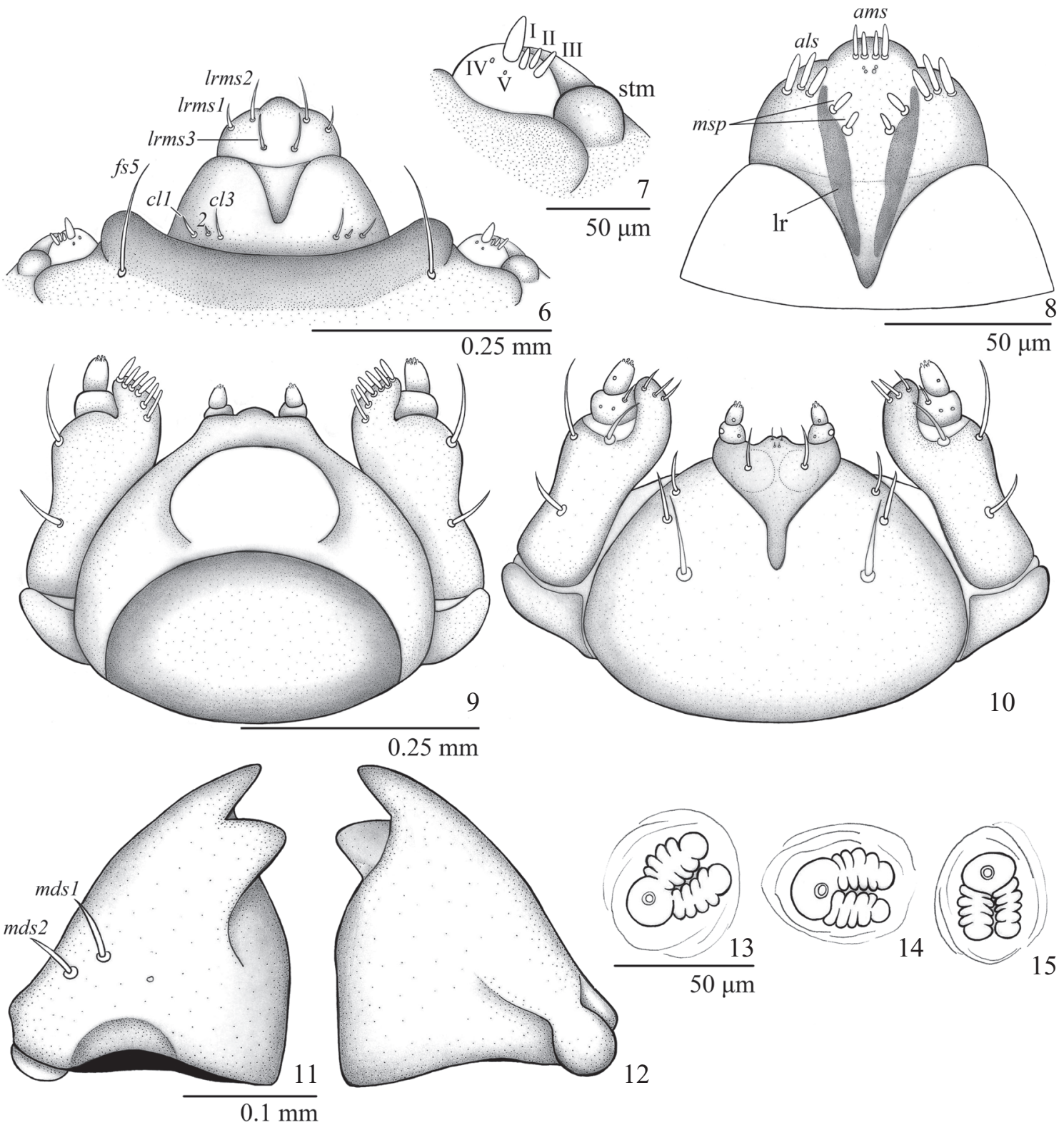

Figs. 6-15. Anthonomus vis, third instar larva. 6, clypeus and labrum; 7, antenna; 8, epipharynx; 9, hypopharynx; 10, labium; 11, mandible (ventral view); 12, mandible (dorsal view); 13, prothoracic spiracle; 14, abdominal spiracle I; 15, abdominal spiracle VIII. Legends [seta(ae), s.]: als, anterolateral s.; ams, anteromedian s.; cls, clypeal s.; $f s$, frontal s.; msp, median spines; $l r$, labral rods; lrms, labral s.; mds, mandibular setae; mes, median setae.

to Brazil, ranging from Minas Gerais and Rio de Janeiro through São Paulo and Paraná south to Santa Catarina (Baumgratz \& Souza 2011).

Biology. Anthonomus vis is an inquiline in a spherical, reddish and hairy stem-gall induced by a momphid moth (Momphidae, Lepidoptera) in Leandra aurea. Observations on inquilinism were described by Maia \& Fernandes (2004) and Maia \& Oliveira (2004).

\section{DISCUSSION}

A few papers have reported gall inquilinism by species of Anthonomus. For instance, Gates \& Burke (1972) and
Burke (1976) listed seven species of Anthonomini developing as inquilines in galls induced by other organisms. Among them, it is included $A$. convictus Gates, 1972 which develops in galls induced by the moth Heliozella aesella Chambers, 1877 (Heliozellidae) on leaves of Vitis mustangensis Buckl. (Vitaceae), in the USA.

Four species of the $A$. partiarius group are associated with Melastomataceae: A. coactus Clark, 1992 was reared from seeds of Tibouchina multiceps Cogn. (Clark 1992); A. partiarius Boheman, 1843 and A. opis Clark, 1992 are associated with Tibouchina cerastifolia (Naud.) Cogn. (Caxambu 2003), and $A$. vis with Leandra aurea (Maia \& Fernandes 2004; Maia \& Oliveira 2004). 

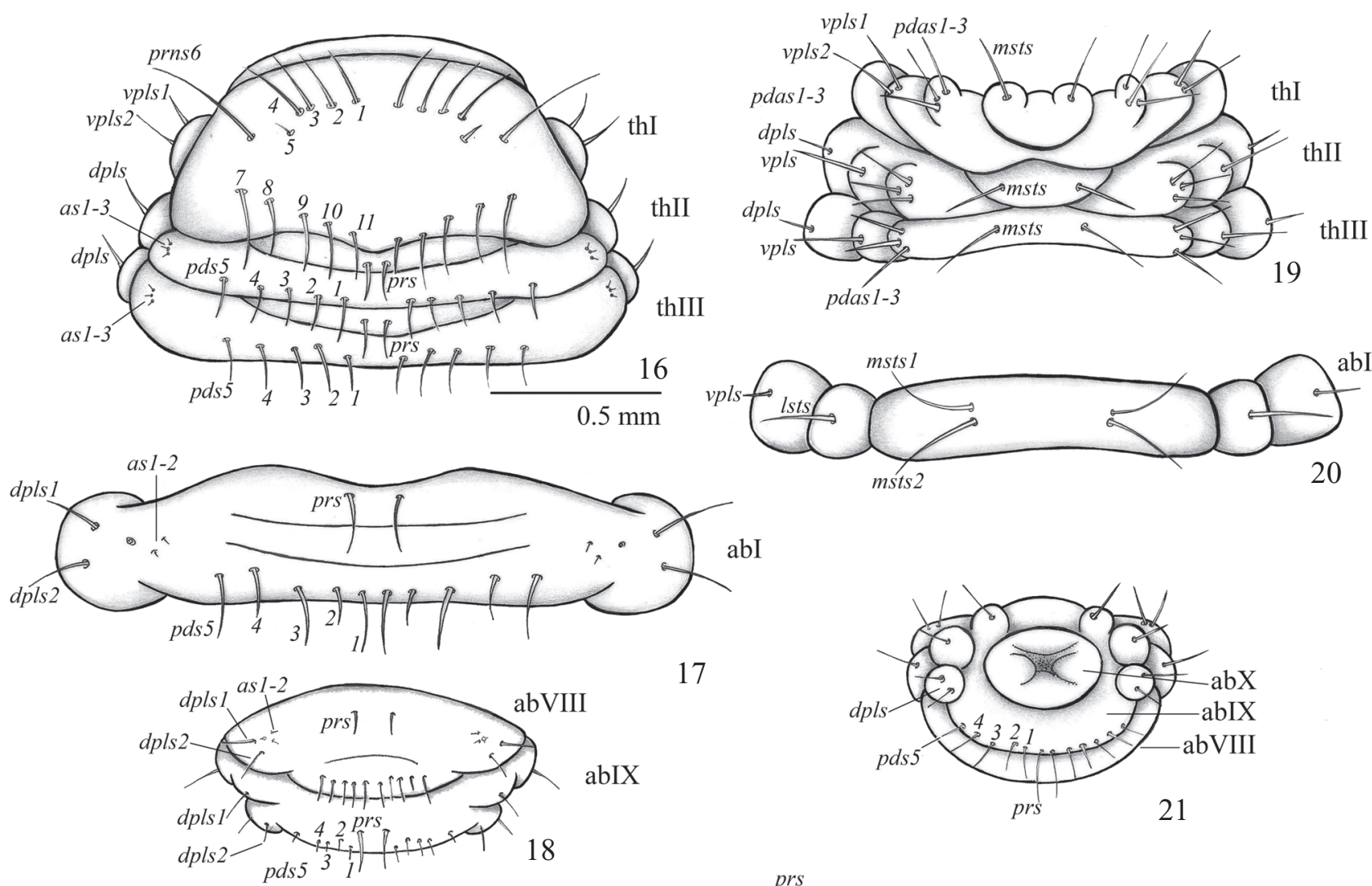

17
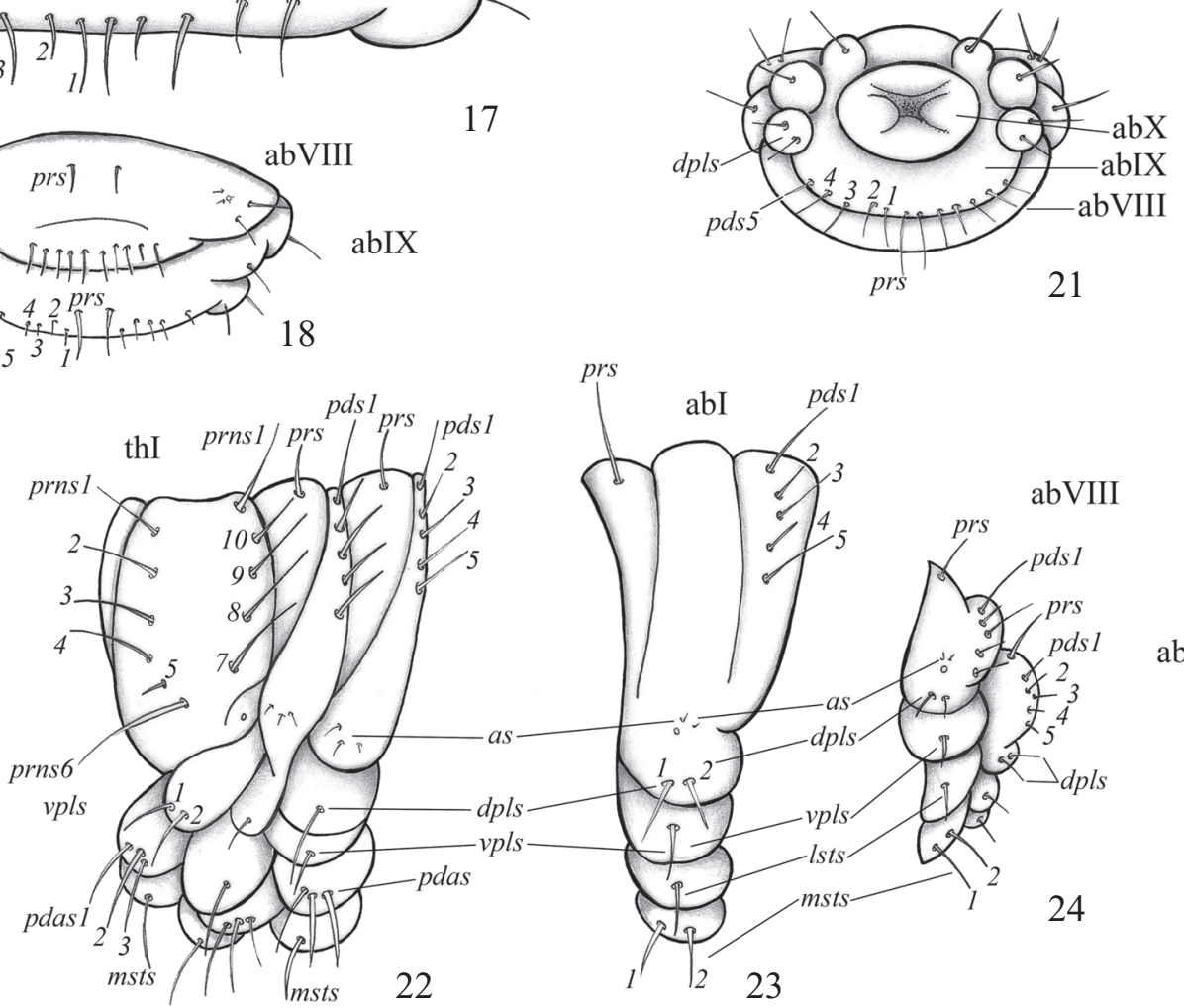

abIX

Figs. 16-24. Anthonomus vis, third instar larva. Thoracic segments: 16, dorsal; 22, lateral; 19, ventral. Abdominal segment I: 17, dorsal; 23, lateral; 20, ventral. Abdominal segments VIII-IX: 24,lateral; 21, ventral. Legends [seta(ae), s.]: as, alar s.; dls, dorsolateral s.; dpls, dorsopleural s.; lsts, laterosternal s.; msts, mesosternal s.; pdas, pedal s.; $p d s$, postdorsal s.; prns, pronotal s.; prs, prodorsal s.; ss, spiracular s.; vpls, ventropleural s.; pd, postdorsum; Ab, abdominal segment; Th, thoracic segment.

Chacón-Madrigal et al. (2012) reported the biology and described the third instar larva and pupa of A. monostigma Champion, 1903, a species that is included in the $A$. monostigma species group. The larvae feed on and develop in fruits of three species of Miconia (Melastomataceae), in Costa Rica. Considering host relationships, Chacón- Madrigal et al. (2012) suggested that the A. monostigma species group could be related to the $A$. partiarius and the $A$. albocivitensis species groups (sensu Clark 1992, 1993).
The present descriptions are the first published of larva and pupa for a species of the $A$. partiarius species group. The larvae of $A$. vis and $A$. grandis (A. grandis species group) are also very similar, differing as follows (characters of $A$. grandis in parentheses, according to Ahmad \& Burke 1972): des2des 3 more aligned (not aligned); $f_{s} 2$ inserted close to frontal suture (distantly located from frontal suture); $f s 5$ longer, its tip surpassing clypeo-labral suture ( $f s 5$ shorter, not attaining fronto-clypeal suture); projection of tentorial bracon elongate, 

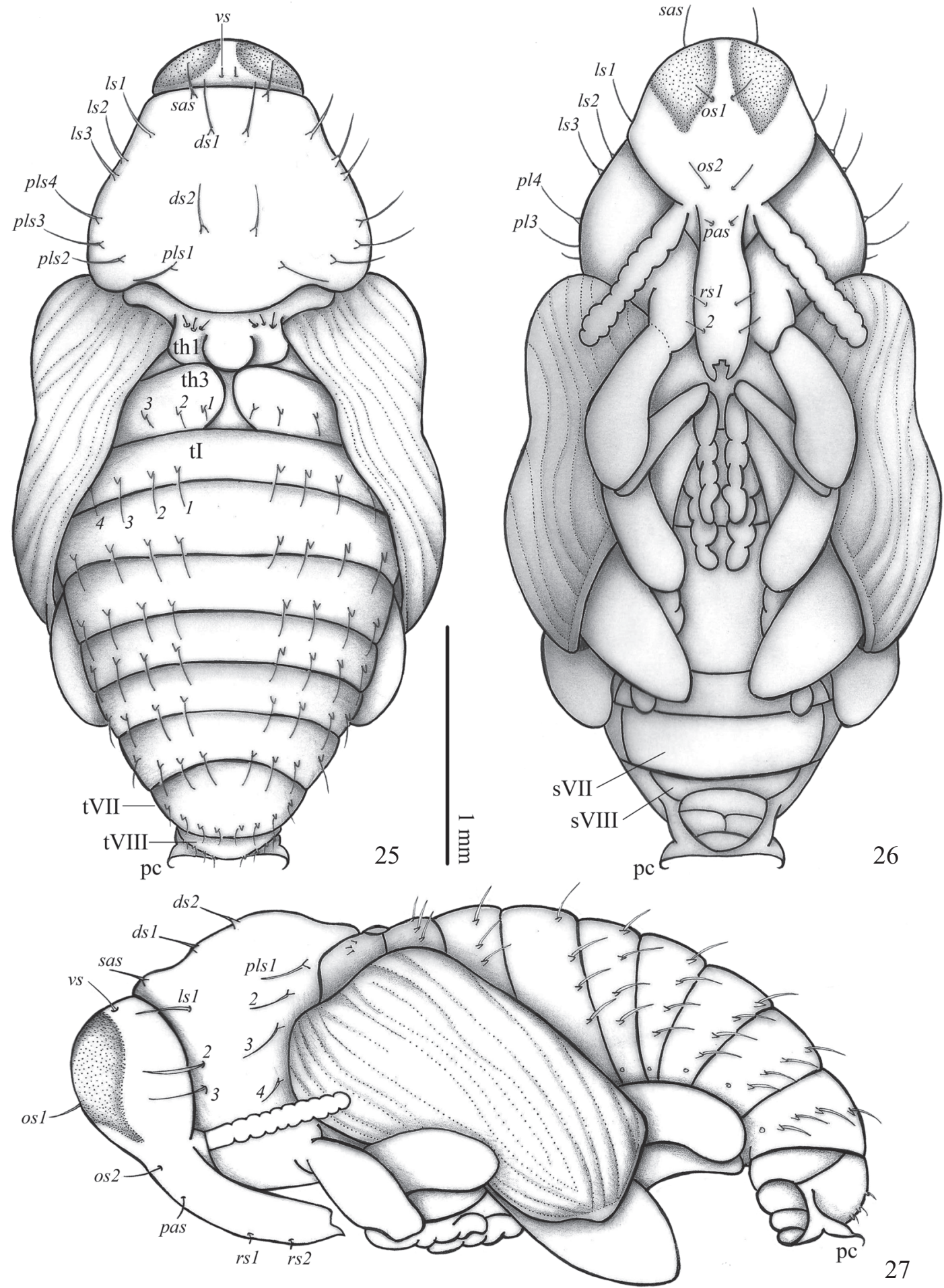

Figs. 25-27. Anthonomus vis, pupa. Habitus: 25, dorsal view; 26, ventral view; 27, lateral view. Legends [seta(ae), s.]: $d s$, discal s.; $l s$, lateral s.; os, orbital s.; pas, postantennal s.; pls, posterolateral s.; $r s$, rostral s.; sas, super apical s.; os, orbital s.; $v s$, vertical setae; pc, pseudocerci; SVII, sternite VII; SVIII, sternite VIII; ThI, thoracic tergite I; ThII, thoracic tergite II; ThIII, thoracic tergite III; TVII, abdominal tergite VII; TVIII, abdominal tergite VIII.

about twice as long as wide (very short, forming a weak protuberance). The female pupa of $A$. vis and $A$. grandis can be distinguished by the length of the rostrum. The tip of the rostrum slightly surpasses the procoxae in $A$.vis, while in $A$. grandis it exceeds the third ventrite (Burke 1968). The main differ- ences between the larvae of $A$. vis and $A$. monostigma are (characters of $A$. monostigma in parentheses): $f_{s} 5$ longer, its tip surpassing clypeo-labral suture $\left(f_{s} 5\right.$ shorter, not exceeding the margin of the cephalic capsule); $f_{s} 2$ inserted close to frontal suture (distantly placed from frontal suture). The pupa of $A$. 
vis has two pairs of rostral setae, rs1 and rs2 (one pair of "distirostral setae", according to the terminology of Burke (1968), followed by Chacón-Madrigal (2012)); pseudocerci transverse, not pedunculate (pedunculate and bifurcate at apex).

Anthonomus vis was previously reported for the Brazilian Amazonian region, in the states of Amapá and Pará (Clark 1992). This new record for the state of Minas Gerais extends the distribution southwards to southeastern Brazil. Other species of the $A$. partiarius species group also have wide distributions in South America, such as A. imperium Clark, 1992 (Venezuela and central Brazil), A. gravatis Clark, 1992 (Mato Grosso and Minas Gerais, in Brazil, and Venezuela), and $A$. valentis Clark, 1992 (Amapá, Goiás and Mato Grosso, in Brazil, Suriname and Venezuela). The host species of $A$. vis, Leandra aurea ranges from Minas Gerais and Rio de Janeiro to Santa Catarina (Baumgratz \& Souza 2011), but the genus Leandra Raddi has a Neotropical distribution, occurring in tropical and temperate regions with about 200 species, distributed from Mexico and the Antilles south to Argentina, mainly in grassland and rainforest habitats (Baumgratz \& Souza 2011). Further studies are needed to discover the host plant of $A$. vis in the Amazonian region.

\section{ACKNOWLEDGMENTS}

We would like to thank Dr. Valéria Cid Maia (Museu Nacional, Quinta da Boa Vista, Universidade Federal do Rio de Janeiro) for making the immatures and adults of Anthonomus vis available for study, Dr. Ricardo Pinto da Rocha (Instituto de Biociências, Universidade de São Paulo) for providing access to his photo equipment (FAPESP 2008/ 06604-7), Bruno A. S. de Medeiros for the photos, Ricardo Pires Vanin for the electronic treatment of the photographs, and Juares Fuhrmann for assistance with editing the figures.

\section{REFERENCES}

Ahmad, M. \& Burke, H.R. 1972. Larvae of the weevil tribe Anthonomini (Coleoptera: Curculionidae). Miscellaneous Publications of the Entomological Society of America 8: 31-81.

Alonso-Zarazaga, M.A. \& Lyal, C.H.C. 1999. A World Catalogue of Families and Genera of Curculionoidea (Insecta: Coleoptera)
(Excepting Scolytidae and Platypodidae). Barcelona, Entomopraxis, $315 \mathrm{p}$.

Baumgratz, J.F.A. \& Souza, M.L.D.R. 2011. Melastomataceae na Reserva Ecológica de Macaé de Cima, Nova Friburgo, Rio de Janeiro, Brasil. II - Leandra (Miconieae). Rodriguésia 62: 629-662.

Burke, H.R. 1968. Pupae of the weevil tribe Anthonomini (Coleoptera: Curculionidae). Texas Agricultural Experiment Station, Technical Monographs 5: 1-92.

Burke, H.R. 1976. Bionomics of the anthonomine weevils. Annual Review of Entomology 21: 283-303.

Caxambu, M.G. 2003. Anthonomus partiarius Boheman, 1843 (Coleoptera, Curculionidae) associado a Tibouchina cerastifolia (Naud.) Cogniaux (Melastomataceae): formas imaturas, aspectos bioecológicos e testes de especificidade. Ph.D. dissertation. Curitiba, Universidade Federal do Paraná, $71 \mathrm{p}$.

Chacón-Madrigal, E., Johnsom, M.T. \& Hanson, P. 2012. The life history and immature stages of the weevil Anthonomus monostigma Champion (Coleoptera: Curculionidae) on Miconia calvescens DC (Melatomataceae). Proceedings of the Entomological Society of Washington 114: 173-185.

Clark, W.E. 1992. The Anthonomnus partiarius species group (Coleoptera: Curculionidae). Transactions of the American Entomological Society 118: 107-128.

Clark, W.E. 1993. The Anthonomus ouratae, A. planipennis and A. albocivitensis species groups, and new species in the $A$. rubiginosus and $A$. partiarius groups (Coleoptera: Curculionidae). Transactions of the American Entomological Society 119: 247-269.

Clark, W.E. 2013. List of Species of Curculionidae (Coleoptera) assigned to the tribe Anthonomini. Available at: http://www.auburn.edu/ clarkwe/anthspp.htm (accessed 8 January 2013).

Gates, D.B. \& Burke, H.R. 1972. Review of the gall-inhabiting weevils of the genus Anthonomus, with description and biology of a new species (Coleoptera: Curculionidae). Annals of the Entomological Society of America 65: 1215-1224.

Maia, V.C. \& Fernandes, G.W. 2004. Insect galls from Serra de São José (Tiradentes, MG, Brazil). Brazilian Journal of Biology 64: 423-445.

Maia, V.C. \& Oliveira, J.C. 2004. Coleoptera associated with galls from South America with new records. Arquivos do Museu Nacional 62: 179-184.

May, B.M. 1994. An introduction to the immature stages of Australian Curculionoidea, p. 365-728. In: Zimmerman, E.C. (ed.). Australian Weevils. Vol. 2. Melbourne, CSIRO, $\mathrm{x}+755 \mathrm{p}$.

O'Brien, C.W. \& Wibmer, G. C. (1982) Annotated checklist of the weevils (Curculionidae sensu lato) of North America, Central America, and the West Indies (Coleoptera: Curculionoidea). Memoirs of the American Entomological Institute 34: $\mathrm{ii}-\mathrm{x}+1-1755$.

Wibmer, G.C., O'Brien C.W. 1986. Annotated checklist of the weevils (Curculionidae sensu lato) of South America (Coleoptera: Curculionoidea). Memoirs of the American Entomological Institute 39: $\mathrm{i}-\mathrm{xvi}+1-563$.

Received 21 January 2013; accepted 9 October 2013

Associate Editor: Lucia M. Almeida 